\title{
Influence of Drug-Silica Electrostatic Interactions on Drug Release from Mesoporous Silica-Based Oral Delivery Systems
}

Siddhi S. Hate, ${ }^{\dagger}$ Susan M. Reutzel-Edens, ${ }^{\ddagger}$ Lynne S. Taylor ${ }^{\dagger *}$

${ }^{\dagger}$ Department of Industrial and Physical Pharmacy, College of Pharmacy, Purdue University, West Lafayette, Indiana 47907, United States

${ }^{\ddagger}$ Lilly Research Laboratories, Eli Lilly and Co., Indianapolis, 46285, United States.

*To whom correspondence should be addressed: 1staylor@purdue.edu

\section{Supporting Information}

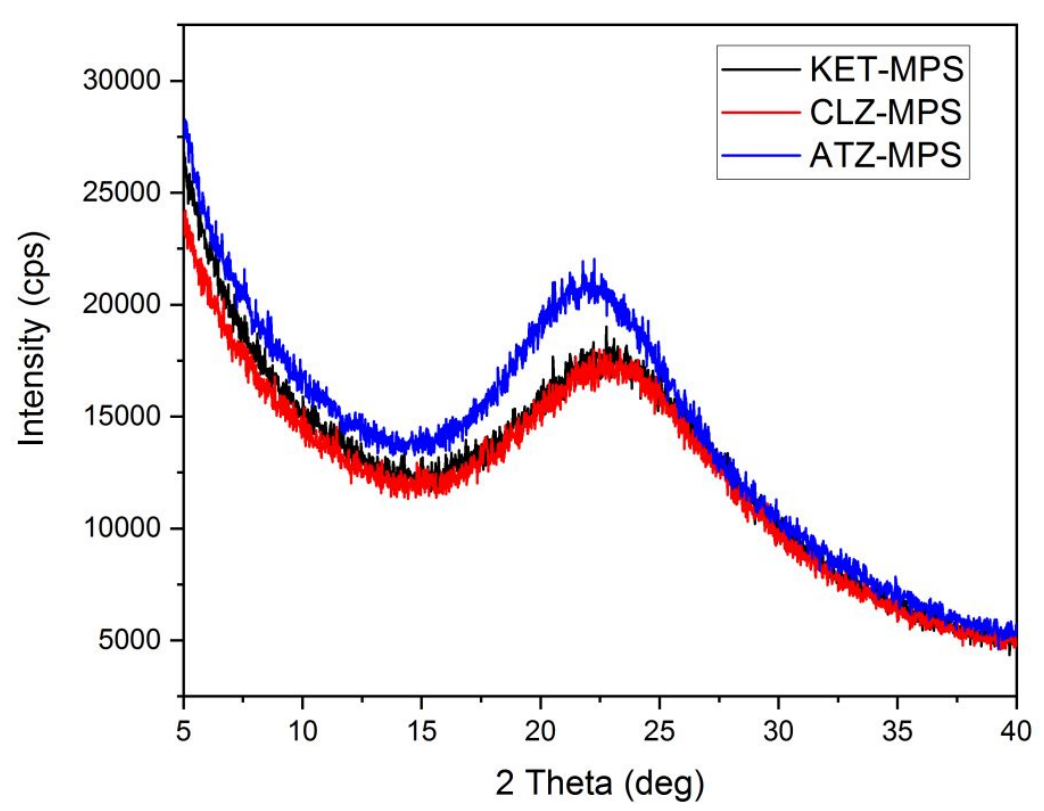

Figure S1: Powder X-ray diffraction of 20\% KET, CLZ and ATZ-loaded mesoporous silica formulation. 

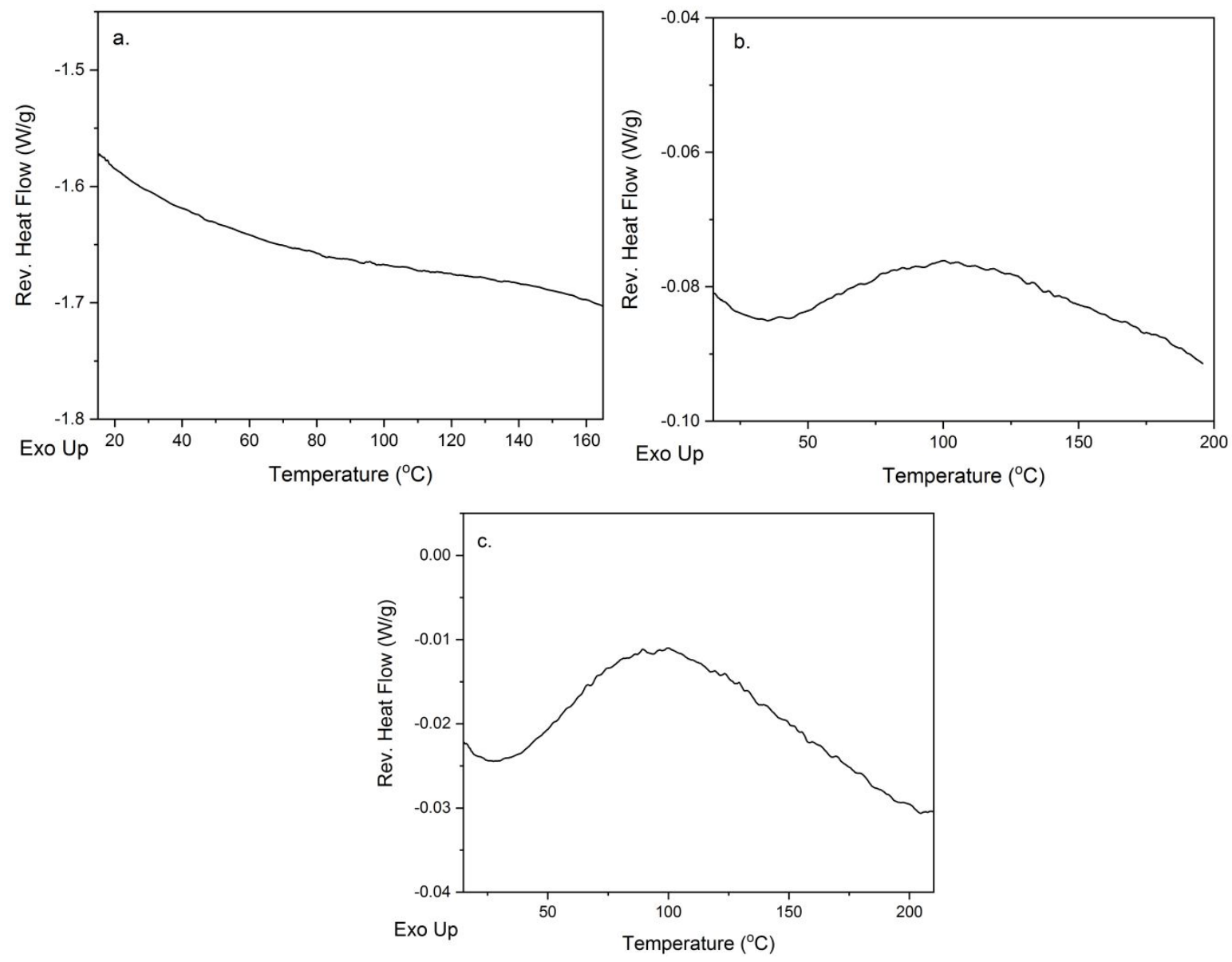

Figure S2: DSC thermograms of (a) KET-MPS (b) CLZ-MPS and (c) ATZ-MPS formulations. No evidence of $\mathrm{T}_{\mathrm{g}}$ suggests nanoconfinement of drug in silica pores. 


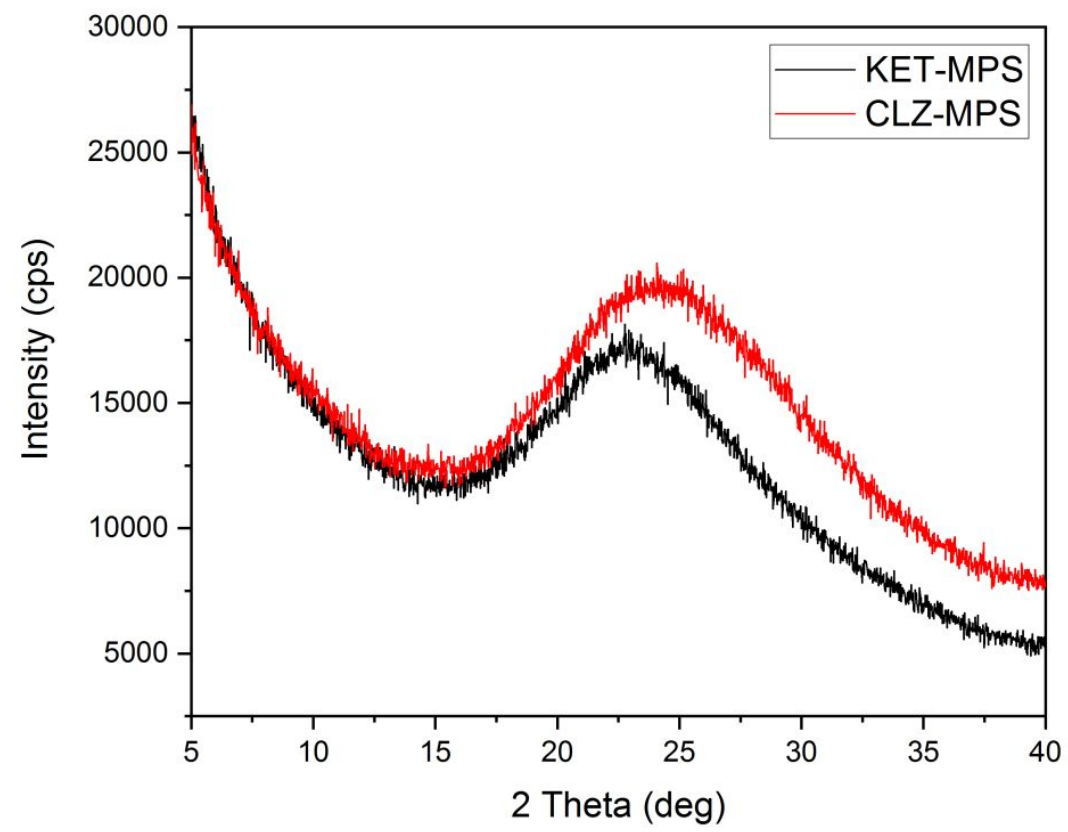

Figure S3: Powder X-ray diffraction of precipitate collected after two-step dissolution of $20 \%$ KET and CLZ-loaded mesoporous silica formulation with $\mathrm{pH}$-shift from $\mathrm{pH} 1$ to $\mathrm{pH} 6.8$.

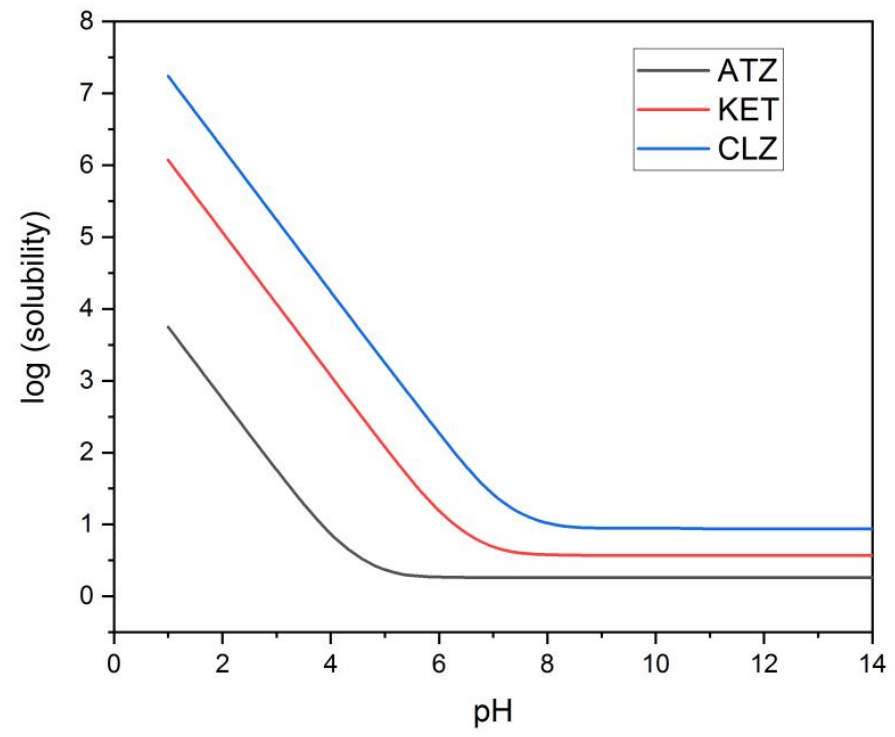

Figure S4: pH-solubility profiles of crystalline KET, CLZ and ATZ predicted using the Henderson-Hasselbalch equation. 


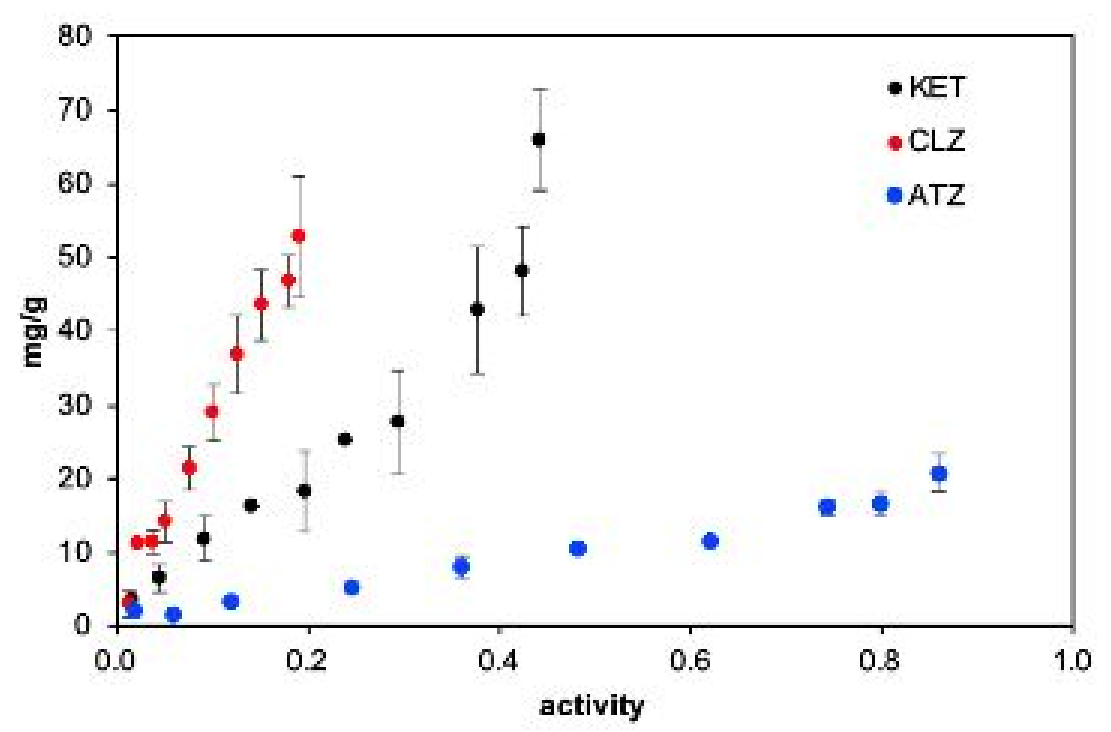

Figure S5: Adsorption isotherm of KET, CLZ and ATZ as a function of solute activity at pH 6.8 where solute activity was estimated from the equilibrium concentration following adsorption divided by the amorphous solubility.

Table S1: Monolayer coverage, $\mathrm{Q}_{\mathrm{m}}(\mathrm{mg} / \mathrm{mol})$, for KET, CLZ and ATZ estimated by fitting the adsorption isotherms to the BET equation.

\begin{tabular}{|c|c|c|c|c|}
\hline & pH 1 & pH 4.5 & pH 5.5 & pH 6.8 \\
\hline KET & 0.022 & 0.081 & 0.125 & 0.118 \\
\hline CLZ & & 0.049 & 0.098 & 0.275 \\
\hline ATZ & 0.057 & 0.058 & 0.019 & 0.006 \\
\hline
\end{tabular}

